\title{
Fichte y Pestalozzi. Sobre la educación del pueblo
}

\author{
Fichte and Pestalozzi. On the education of the people
}

\author{
Jacinto Rivera de Rosales \\ jrivera@fsof.uned.es \\ (Universidade Nacional de Educação à Distância, Madrid, España)
}

\begin{abstract}
Resumen: Fichte, en sus Discursos a la Nación alemana, consideró que la pedagogía de Pestalozzi era la correcta para los nuevos tiempos y la adecuada para entender su filosofía. Ambos pensaban que la educación había de ser accesible a todos, sin distinción de estamentos o clases, una educación del pueblo que Fichte convierte en educación nacional. Se ha de educar equilibradamente todas las fuerzas y capacidades del ser humano, atendiendo asimismo a las etapas de su desarrollo evolutivo. La intuición ha de ser la base de esa educación, que ha de potenciar la capacidad de pensar y actuar por sí mismo.

Palabras clave: Fichte; Pestalozzi; educación; intuición; acción.
\end{abstract}

\begin{abstract}
Fichte, in his Addresses to the German Nation, considered that the pedagogy of Pestalozzi was the right one for the new times and the right one for understand his philosophy. Both thought that education was to be accessible to all people, regardless of states or classes, an education of the people that Fichte turns into national education. All human forces and capacities must be educated in a balanced manner, also attending to the stages of their evolutionary development. Intuition must be the basis of that education, which must enhance the ability to think and act for himself.
\end{abstract}

Keywords: Fichte; Pestalozzi; education; intuition; action.

Fichte y Pestalozzi compartían algunos elementos que les acercaron el uno al otro. En primer lugar, la ciudad de Zúrich, donde nació Pestalozzi y en la que Fichte residió algún tiempo y encontró a la que fue mujer, Johanne, amiga de la de Pestalozzi. En 1788 Fichte había ya apreciado la novela de Pestalozzi Leonardo y Gertrudis, en donde, según él, se abordaba de manera apropiada el tema de la miseria del pueblo (GA II/1, p.104). En ese relato rural se defendía la educación como medio para resolver los males sociales y políticos. Pestalozzi había obtenido un gran éxito con ese libro, llegando a ser el único suizo nombrado Ciudadano de Honor por la Asamblea Nacional Francesa. En 1793-4, ambos llegaron a conocerse personalmente y a estimarse (Fuchs, 1978, pp.66-74), y Fichte, a principios de 1794, proyectó escribir una reseña de la novela (GA III/8, p.152). Según Pestalozzi, Fichte le hizo ver por aquel entonces que sus experiencias pedagógicas le habían conducido cerca de la filosofía kantiana (Pestalozzi, 1949, p.307); pero él declaró después: “desde los 
veinte años he abandonado la filosofía en el estricto sentido de la palabra [...], que me parece tan compleja" (Pestalozzi, 2009, p.94), y que Fichte se encontraba por encima de sus capacidades (Pestalozzi, 1949, p.342). Sin embargo, bajo el impulso de él, Pestalozzi publicó sus pensamientos filosóficos en Mis investigaciones sobre el curso de la naturaleza en el desarrollo de la especie humana (1797), para el que parece que fue importante el Derecho natural de Fichte (1796-7).

Hay que reseñar que ambos eran protestantes y republicanos. Además, compartían una misma lengua, la alemana, lo que, para el Fichte de Berlín, más romántico, significaba también pertenecer a un mismo pueblo o nación, aunque ésta estuviera dividida en diversos Estados independientes. Por último, compartieron un interés común por la educación de todos los ciudadanos. Pestalozzi la tomó como la vocación de toda su vida, en cuanto medio para salvar al pueblo de sus miserias (Pestalozzi, 2009, pp.23-24), como ocurría en su novela. Para Fichte, la educación era un elemento esencial para devenir un ser humano y racional y para la construcción de una sociedad de hombres libres.

En sus Aforismos sobre la educación, del año 1804, escritos con motivo de la crianza de su hijo, aún no hace referencia a Pestalozzi, ni en las tres exposiciones que escribió sobre el destino del erudito (1794, 1806 y 1811), pues estaban destinadas a los universitarios. El encuentro se produjo en 1807-8 en el contexto de los Discursos a la Nación alemana, a raíz del proyecto de Fichte de salvar a Alemania tras su derrota frente a Napoleón por medio de una revolución cultural. Ya en La República de los alemanes (inicios de 1807, no publicado) se dice a sí mismo que para avanzar en el tema de la educación "tengo que leer a Pestalozzi" (GA II/10, p.390). En carta del 3-6-1807 le aconseja a su mujer que lea Cómo Gertrudis enseña a sus hijos de Pestalozzi, con el que éste había obtenido su segundo gran éxito: "Ahora estudio el sistema educativo de ese hombre y encuentro en él el verdadero remedio para la humanidad enferma, así como también el único medio para hacerla apta a la comprensión de la Doctrina de la Ciencia" (GA III/6, p.121). Se conservan las notas que fue tomando Fichte durante esa lectura, con comentarios y observaciones, también críticas a la idea que tiene Pestalozzi de la abstracción, a su empirismo, su no distinción entre sentimientos e intuiciones, su falta de filosofía (GA II/10, pp.431457). Le interesaron igualmente los escritos de Pestalozzi El libro de las madres, de 1803 (Fichte, 1988, pp.165-6), e Ideas, experiencias y medios para la promoción de una manera de educar adecuada a la naturaleza humana de 1807 (GA III/6, p.121). Al final del segundo diálogo sobre El patriotismo y su contrario (1807), que tampoco publicó, Fichte habla en sentido elogioso de Pestalozzi, resaltando su pedagogía de la intuición, aunque critica de nuevo su empirismo (GA II/9, pp.436-444), de modo que Fichte juzga a Pestalozzi como antes lo hizo con Kant: conoce los resultados, pero no ha captado los principios, es decir, no ha entendido bien sus propios fundamentos, 
de manera que su genial pensamiento, creado en realidad por la razón eterna, es superior a él mismo (ídem, p.438).

Mas el momento cumbre se produce en los Discursos, que fueron publicados con gran éxito (1808). Para construir una nación alemana libre y liberadora Fichte propone una nueva educación (Discursos 1-3), y declara que ésta ya ha sido diseñada y felizmente practicada por Pestalozzi (Discursos 9-12; ver también GA IV/6, p.344). Esto supuso un significativo espaldarazo para Pestalozzi, que ese mismo año fue nombrado Miembro externo de la Academia de Ciencias de Baviera. Veamos, articulado en 6 puntos centrales, ese nuevo concepto de educación que Fichte elabora leyendo a Pestalozzi. ${ }^{1}$

\section{Una educación para todos}

La primera idea, la que fundamenta todo el discurso de ambos, es que la educación representa un momento esencial en la formación del ser humano libre. "El hombre únicamente puede llegar a ser hombre por medio de la educación" a través de otros seres humanos, dice Kant en su Pedagogía (AA 9: p.441), pues sólo así llega a ser capaz de ejercer su razón. "El hombre [...] sólo por el arte [de educar] llega a ser hombre”, escribe Pestalozzi (2009, p.84). Únicamente así puede elevarse de las intuiciones confusas a los conceptos exactos (ídem, p.85). Por eso la educación es esencial para el ser humano y la sociedad, de manera que todos tienen igual derecho a ella (ídem, pp.115, 125). Por eso él se dedicó a la enseñanza de los niños abandonados y pobres, viendo en la educación el mejor medio para superar la miseria y alcanzar la virtud y la felicidad (ídem, p.170). Para ese fin era preciso una nueva educación, dado que la enseñanza escolar de su tiempo él no la consideraba apta para las clases inferiores (ídem, pp.114-5). Ha de ser una enseñanza fácil de llevar a la práctica por el educador, que popularice las ciencias y suministre la capacidad mental necesaria para una vida independiente y sabia (ídem, pp.48-50). En consecuencia, era necesario que los materiales de estudio no fueran caros (ídem, pp.50-1). Más aún, había que proveer a las madres de procedimientos y materiales pedagógicos, a fin de que ellas educaran a sus hijos desde la cuna.

En los primeros parágrafos de la Fundamentación de derecho natural, Fichte deduce la naturaleza intersubjetiva o comunitaria del ser humano como fundamento del derecho. El destino del hombre es saberse y realizarse como un ser libre y racional y eso únicamente es alcanzable en comunidad, o sea, en interacción con otros seres humanos, en la que opera el requerimiento (Aufforderung) de los unos a los otros a actuar racionalmente:

1 Una visión general de la pedagogía de la época con traducción de textos se puede encontrar en Quintana, 2013. 
El ser humano [...] sólo entre seres humanos llega a ser un ser humano; y como no puede ser otra cosa que un ser humano, no existiría si no lo fuera. Luego si deben existir seres humanos en general, entonces han de ser varios. [...] El requerimiento a la actividad propia libre es lo que se llama educación (GA I/3, p.347).

Por consiguiente, la educación es una condición transcendental de la subjetividad racional, de todo ser humano. El Yo transcendental, como primer principio del Fichte de Jena, es acción real e ideal, libertad y saber, y de él se deduce tanto el individuo como la comunidad, ambos igualmente necesarios. En consecuencia, esa educación atañe y afecta a ambos, de manera que tiene que ver no sólo con la génesis y desarrollo de cada uno, sino también con la evolución histórica de la humanidad. La plena realización de esa libertad y del saber es una tarea infinita, siempre estamos en camino, y debemos acercarnos asintóticamente a ese ideal (El destino del erudito, $\mathrm{GA}$ I/3, p.32), una tarea que ha de pasar de unas generaciones a otras por medio de la educación.

Lo mismo ocurre en el segundo Fichte (1801-1814), ${ }^{2}$ en donde están enmarcados los Discursos a la Nación alemana, pues todos los seres humanos y el mundo entero no son sino el desarrollo del saber absoluto, el cual es manifestación e imagen del Ser absoluto o Dios, y el saber es esencialmente un saber-se. Los seres humanos deben por ende llegar en sí mismos a la plena realización de dicho saber / saberse en cuanto lugares privilegiados de esa vida divina (Fichte, 1988, p.49), para lo cual la educación constituye un elemento indispensable. En consecuencia, todos han de tener acceso a la educación, y por eso ésta ha de estar organizada y financiada por el Estado (Fichte, 1988, pp.189 ss.), lo cual en ese momento histórico estaba lejos de ser realidad. "Hasta ahora, esta formación limitada llegó solamente a una pequeña minoría” (ídem, p.25) y aspiraba únicamente a conseguir cierta habilidad en las cuestiones materiales. La que ahora se requiere es una formación de todo el pueblo y en cierto sentido una educación nacional que no prescinda del ámbito del sentir ni de la filosofía (ídem, p.59).

\section{Educación del pueblo, educación nacional, educación superior}

La educación del pueblo (Volkserziehung) que quería Pestalozzi se transforma en Fichte en educación nacional (Nationalerziehung), pues ella debe hacer posible la recuperación de la Nación alemana subyugada por Francia y, más aún, hacer desaparecer los estamentos (Stände), las clases sociales, tareas que no había previsto Pestalozzi. Todos deben tener por igual una educación, así como todos han de poder

\footnotetext{
2 Para una exposición general de Fichte y distinción de sus dos etapas, véase Rivera de Rosales, 2017, y para el paso de una etapa a otra véase Rivera de Rosales, 2019a. En Fichte, 2019, pp. 7-21, se ha traducido, con notas aclaratorias, la única Doctrina de la Ciencia del segundo Fichte que él llegó a publicar, a saber, el resumen de su exposición de 1810.
} 
vivir de su trabajo (eso es lo que sostiene Fichte en El Estado comercial cerrado), configurándose de esa manera una verdadera comunidad nacional.

Con la nueva educación nosotros queremos hacer de los alemanes un todo [...] una formación de la nación y sin exceptuar a ninguno de sus miembros, y que así desaparezca [...] toda diferencia de estamentos [...] hasta el punto de que surja entre nosotros no una educación del pueblo [a diferencia de las clases altas], sino una educación nacional propia de alemanes (ídem, p.25).

D. Tröhler sostiene que "Pestalozzi es la figura principal de un particular cambio cultural que se produjo en torno a 1800 y que se puede etiquetar como un 'giro educativo'” (2014, p.11) en Europa y en Estados Unidos, consistente en tomar la educación como clave para la resolución de problemas sociales y políticos.

Tanto Pestalozzi como Fichte vieron en la formación del pueblo el presupuesto necesario para una democracia. Su acción fue revolucionaria bajo ese punto de vista. Sin la recepción de Pestalozzi por parte de Fichte no hubiera sido posible el movimiento democrático alemán, que encontró un desenlace provisional en la Paulskirche (Taver, 2012, p.418),

o sea, en el Parlamento de Fráncfort en 1848-9, congregado en la iglesia de San Pablo de esa ciudad, y su Constitución para una Alemania unida.

Fichte distingue entre la educación nacional y la educación superior (Gelehrtenerziehung), la universitaria, la dirigida a los que han de convertirse en eruditos (Gelehrten). Ésta se apoya en la primera, mas no es para todos los ciudadanos, sino sólo para aquellos más capacitados, los que muestren "dotes excelentes para aprender y una inclinación muy marcada hacia el mundo de los conceptos", pero sin diferencia de clase social o económica, "pues la clase de origen no diferencia realmente las aptitudes" (ídem, p.172) y "todo talento es una propiedad estimable de la nación que no le debe ser arrebatada" (ídem, pp.186-187). Estos alumnos más aventajados no deben hacer trabajos manuales durante la educación nacional, sino ocupar ese tiempo con el estudio, porque su misión es promover el saber que nos constituye. Por eso, dicha educación superior es necesaria para la humanidad, y dado que esa tarea de la razón es inmensa, se deben distribuir los individuos en los distintos ámbitos del saber, al igual que ocurre con los otros trabajos necesarios para la sociedad (unos son carpinteros, otros albañiles o labradores, etc.), y es en realidad una labor de toda la humanidad. Por consiguiente, aunque sólo algunos harán esa educación superior, todos han de beneficiarse de ella. En Iniciación a la vida bienaventurada (1806) Fichte sostiene que no es necesario ser filósofo para alcanzar una vida plena, pero el destino y la tarea del hombre es llegar al pensar puro y autónomo para ser persona libre (GA I/9, pp.68-9) y lograr la máxima claridad en el saber, "pues la claridad lograda en todas las direcciones pertenece a la imagen y expresión de Dios" (ídem, p.112) que es lo que ha de llegar a ser el hombre. Por 
eso, aquel que no pueda alzarse a los principios filosóficos de manera sistemática y escolar mediante estudios superiores, ése ha de recibir al menos noticia de ellos mediante una exposición popular de los mismos (ídem, pp.70-71), y esto es lo que intenta hacer Fichte con sus escritos populares, como son la Iniciación y sus Discursos. Pestalozzi únicamente se dedicó a la educación primaria, mas Fichte consideró que su pedagogía era la que ponía la base más adecuada para la superior y para la comprensión de su Doctrina de la Ciencia, justamente porque se apoyaba en la intuición y en la actividad del educando, como veremos.

La siguiente distinción se establece entre la educación del pueblo y la educación nacional. El término de "educación nacional" señala la mayor ambición con la que Fichte proyecta el sentido y el alcance de la educación. Según él, el proyecto de Pestalozzi era demasiado corto, y las malas interpretaciones que había cosechado procedían del "objetivo insuficiente y limitado que sirvió de punto de partida" (Fichte, 1988, p.163). Pestalozzi no buscaba reformar la sociedad, la dejaba como estaba, sin afectar su división en estamentos, y sólo pretendía "prestar la ayuda mínima necesaria a los niños procedentes del pueblo totalmente abandonados" (ídem, p.163) y que dejaran pronto la escuela para ganarse la vida. Fichte, por el contrario, juzga que "el educando tiene que permanecer en la educación de manera incondicional y a costa de cualquier riesgo todo el tiempo necesario para que ésta se termine [...] Una educación a medias no es mejor que la ausencia total de ésta" (ídem, p.164). Por eso hay en Pestalozzi, según Fichte, una excesiva valoración del saber leer y escribir como el máximo objetivo, que por sí solos contradicen su principio fundamental de la intuición directa y dejarían al hombre en las sombras y la arrogancia, con el riesgo de quedarse en la letra sin intuición, sin comprender su significado; el simple signo lingüístico no eleva al hombre a la claridad y la precisión del conocimiento (ídem, pp.164-8). Pestalozzi no vio la carga revolucionaria de su nueva pedagogía, porque le faltaba estudios filosóficos para comprender esa posibilidad y necesidad de transformar a los hombres por medio de ella (ídem, p.169). Había buscado sus principios pedagógicos por caminos empíricos, aunque veremos que también partió de principios racionales en esa búsqueda. Pero su método puede conducir a una meta más alta, sostiene Fichte; su idea es mejor que él. Pestalozzi y Lutero "representan los rasgos fundamentales del espíritu alemán" (ídem, p.161), puede servir para el ambicioso proyecto de crear una nación y una nueva humanidad libre y consciente.

Nosotros, por nuestra parte, hemos hablado no de la educación del pueblo en contraposición a la de las clases superiores, ya que no deseamos tener por más tiempo pueblo en el sentido de plebe baja y común, ni su existencia puede ser permitida por más tiempo dentro de los asuntos nacionales alemanes, sino que hemos hablado de educación nacional (ídem, p.164; véase también 25).

Dos objetivos, por tanto, le asigna Fichte a esa nueva educación que Pestalozzi 
no tenía en mente. Primero, hacer resurgir a Alemania de su postración. Ante su derrota militar y política frente a Napoleón, la única salida que ve Fichte para el renacimiento de su nación es una revolución cultural, en el espíritu, por medio de una diferente comprensión del mundo (Weltansicht). "El presente ya no nos pertenece [... hay que] esperar un futuro mejor [... ése] es el único elemento en el cual todavía podemos respirar" (ídem, p.195). Los alemanes han de dejar atrás lo que Fichte califica como el tercer período de la historia: el de la Ilustración, cuyo principio consiste en la búsqueda de la mera utilidad por parte del individuo, en su egoísmo, pues éste únicamente puede beneficiar a los vencedores. Hay que pasar decididamente a la cuarta fase de la historia, que consiste en comprender y encarnar individual y colectivamente la nueva filosofía, la iniciada con Kant y llevada a su plenitud por la Doctrina de la Ciencia. Hasta ahora se ha tenido al mundo sensible, al físico, como lo verdaderamente real, pero la nueva filosofía hace ver que el único mundo verdadero es el del espíritu, o sea, que lo más alto no es poseer cosas, sino el saber y la acción libre y creativa, y no es el individuo empírico, aislado y para sí, sino la vida común racional y divina (ídem, pp.159-160). No deseemos otra cosa que la libertad de todos (ídem, p.209). Captar y realizar esa idea es ya vivir la vida divina aquí y ahora. Eso es lo que precisa Alemania, y la pedagogía de Pestalozzi, aderezada con algunos nuevos elementos filosóficos esclarecedores, lo hace posible. De esta manera se alcanzaría la libertad del espíritu y Alemania además iluminaría el camino a las otras naciones, porque el buen patriota comienza con su nación, con lo más cercano y a la mano, pero el fin último es que esa libertad alcance a toda la humanidad ${ }^{3}$. Fichte parte del presupuesto que no es factible ofrecer resistencia militar a los franceses, de manera que únicamente queda salvarse mediante la nueva educación (ídem, pp.29, 194), como individuos y como nación (ídem, pp.23, 157). ${ }^{4}$ Preparémonos para esa nueva generación (ídem, pp.207-209), para “la formación de un yo completamente nuevo" (ídem, p.23), de un yo nacional y comunitario, de un "ciudadano pacífico y auténtico" (ídem, p.160), ${ }^{5}$ dado que el mundo del espíritu "lleva directamente consigo el mayor patriotismo, la concepción de la vida terrena como eterna y de la patria como portadora de esa eternidad" (ídem, p.159).

Por consiguiente, esta educación nacional debe ser un asunto de Estado, como

\footnotetext{
3 Sobre esta articulación entre nacionalismo y cosmopolitismo en el segundo Fichte véase Rivera de Rosales, 2008, pp.345-345.

4 En Rivera de Rosales 2019b se explica que en 1813 Fichte ve ya posible la derrota militar de Napoleón tras el desastre de su campaña de Rusia, y proclama contra él una guerra que considera justificada. También se expone en ese artículo la idea que Fichte tiene de la educación por esos años.

5 "Que el hombre no está en el mundo para sí mismo, que sólo se perfecciona por la perfección de sus hermanos” (Pestalozzi, 2009, p.193). “iNada para mí, sino para mis hermanos! ¿Nada para la propia individualidad, sino para la especie! Este es el fallo absoluto de la ley divina en nuestro interior; en su inteligencia y observancia, se halla lo único noble de la naturaleza humana", decía Lavater (citado por Pestalozzi, 2009, p.196).
} 
también lo pensaba Pestalozzi (2008, pp.177-9). Más aún, su principal tarea y el amor a la patria que procura debe interesarle (Fichte, 1988, 189ss). Hasta ahora la educación ha sido sobre todo una tarea de la Iglesia, pero ella está más interesada en la salvación eterna del hombre, y es "más bien una colonia del cielo aquí en la tierra" (ídem, p.190). Eso debe desaparecer, ya que "la educación para la vida en la tierra es imprescindible, y de la educación esencial para esta vida surgirá por sí misma fácilmente la educación para el cielo" (ídem, p.192); a la religión por la moral, como ya había propuesto Kant. Pero el Estado no se ha preocupado de esa educación, "la respuesta ha sido siempre la misma: el Estado no tiene dinero para esos fines" (ídem, p.191), y sólo ha atendido a veces a la Universidad para prestigio propio. Sin embargo, la educación del pueblo constituye la base del género humano y de ella se nutre la educación superior. En realidad, este gasto en la educación nacional le será muy productivo al Estado: preparará una juventud dispuesta a defender la patria incluso con las armas, mejorará la economía nacional y las instituciones judiciales y policiales, disminuirán las penitenciarías y los reformatorios y no serán necesarias las instituciones benéficas (ídem, pp.191-3).

El segundo propósito de la pedagogía de Fichte es formar una nueva humanidad mediante la visión de la realidad que proporciona la filosofía transcendental y la nueva pedagogía.

Lo único que quería Pestalozzi era ayudar al pueblo; pero su creación, tomada en toda su amplitud, eleva al pueblo, elimina todas las posibles diferencias entre éste y la clase culta, proporciona una educación nacional en vez de la pretendida educación popular y sería capaz de rescatar a los pueblos y a todo el género humano de la profunda miseria actual (ídem, p.162).

La Nación alemana posee la filosofía correcta, o sea, el modo de pensar adecuado a nuestro modo de ser, y además ofrece la pedagogía apropiada para hacérselo entender y vivir a los jóvenes, entonces ésa es su misión dentro de la marcha de la historia humana, y "si la Nación alemana no salva el estado cultural de la humanidad, apenas ninguna otra Nación europea lo hará" (Patriotismo, GA II/9, 436). La nueva educación conduce a la "recreación total del género humano" (ídem, p.159). Con ella "empezaría un orden de cosas totalmente distingo y un mundo nuevo. Para esta nueva configuración la humanidad se crearía a sí misma y por sí misma precisamente al educarse" (ídem, p.57). Para formar esa nueva humanidad, Fichte proponía incluso que el Estado creara centros educativos donde los niños vivieran separados de sus progenitores y del mundo de los adultos, a fin de que éstos no les contagiaran sus angustias, sus mezquindades, su pobre visión del mundo (ídem, pp.42-44, 166, 181 183, 196);

se trata de emprender una transformación total de la humanidad, entonces habrá que arrancarla por completo de sí misma y realizar en ella un corte que la separe de la 
continuidad de su existencia pasada. Solamente después de que toda una generación haya pasado por la nueva educación se podrá deliberar qué parte de la educación nacional se quiere confiar al hogar (ídem, p.166).

Se podría comenzar por los niños abandonados e indigentes, y la escuela de Pestalozzi ha formado ya a educadores competentes (ídem, pp.203-4). Pero en esto Fichte no coincide con Pestalozzi, que da primacía a la educación en la familia, pues el amor, sobre todo el de la madre, es el mejor vehículo para una formación afectiva, ética e incluso intelectual.

\section{Una educación completa y equilibrada}

La educación pública y para todos ha de ser completa, es decir, no una educación meramente intelectual, como solía ser la ilustrada, sino también afectiva, moral y física. Pestalozzi se dirigía hacia un desarrollo completo del alumno, hacia un aprendizaje por la cabeza, la mano (habilidad) y el corazón, decía, que hiciera posible una vida intelectual, moral y técnica de manera equilibrada.

Hay que cultivar de tal modo las facultades de la persona que ninguna de ellas predomine a costa de otra, sino que debe estimularse a cada una según el grado de actividad que justamente le corresponde. Esta situación de ajuste constituye la naturaleza espiritual del hombre (Pestalozzi, 2012, p.20).

En pro de esto, Pestalozzi abogaba además por una educación conjunta de niños y niñas; igualmente Fichte $(1988,182-183)$. Buscaban, por tanto, una educación del querer, del conocer y del poder o habilidad a fin de conseguir una unidad de inteligencia, sentimiento y moralidad, incluyendo también una educación física que fortalezca el cuerpo y le capacite para los diversos fines (ídem, pp.169-171). Pestalozzi ponía especial interés en enseñar a las madres cómo educar, pues el amor materno es el gran recurso educativo (ídem, pp.6-8). La primera instrucción es más un asunto del corazón y de la madre, sólo después lo será de la razón y del padre (Pestalozzi, 2009, p.190).

Fichte, por su parte, piensa que más fuerte que el amor materno es el respeto al padre y la necesidad que tiene el niño de su aprobación como soporte para el esfuerzo necesario en el aprendizaje (1988, pp.173-182). Pero está de acuerdo con la idea de que hay que formar al hombre entero, descuidado en la educación anterior, que únicamente había proporcionado términos y locuciones intelectuales y frías (ídem, pp.23-24, p.434). ${ }^{6}$ La educación es "el arte de formar al hombre en su

\footnotetext{
6 Schiller, en sus Cartas sobre la educación estética del hombre (1795), había criticado la educación meramente intelectual de la Ilustración, culpable de haber llevado a Francia a la época del Terror, y proponía completarla con una educación estética del sentir, que, según él, ponía en armonía sentimiento y razón, el impulso material y el impulso formal del hombre.
} 
totalidad, perfecta e íntegramente", lo cual significa, en cuanto "a la forma, que se modele al hombre auténtico y vital hasta las mismas raíces de su vida", y en cuanto al contenido, "que todos los componentes del hombre sean formados por igual y sin excepción. Estos componentes son el entendimiento y la voluntad; la educación tiene que perseguir la claridad del primero y la pureza de la segunda” (ídem, p.52). Ha de perfeccionar al hombre en todas sus partes (ídem, p.160), convertirle en señor de su fuerza completa, "pues la fuerza de un ser humano es una y es un todo relacionado en sí" (Aforismos, GA II/7, p.12). Tal educación ha sido descubierta y practicada felizmente por Pestalozzi, proclama Fichte (1988, pp.160-1).

Pero si hay que poner el acento en algún aspecto, éste sería la formación ética y cívica, "capaz de determinar y formar las emociones e impulsos vitales de una manera segura e indefectible y de acuerdo con unas normas" (ídem, p.30). Hay que configurar

una generación impulsada simplemente por la complacencia en lo justo y lo bueno y no por otra cosa, dotada de una capacidad intelectual que reconozca siempre con seguridad lo que es suficientemente justo para su punto de vista y que disponga de la fuerza espiritual y física para realizar siempre ese deseo (ídem, p.207).

Esa es la verdadera esencia de la nueva educación, formar al educando en pura ética, de modo que surja "como una obra maestra firme e inmutable" (ídem, p.47). Pues se ha de saber que el educando no es sólo miembro de la sociedad humana en la tierra, sino también y sobre todo "un eslabón de la cadena eterna de la vida espiritual dentro de un orden social superior", y la nueva educación ha de inducirle a que "cree en su pensamiento la imagen de ese orden inmaterial" (ídem p.48). Comprenderá entonces que nada existe realmente a excepción de esa vida divina, que se manifiesta en el pensamiento y en la recta acción, de la que él es un eslabón eterno (ídem, p.49). Para la organización de la sociedad basta la vida ética, pero "la educación en la verdadera religión es la última tarea" (ídem, p.50), ya que gracias a ella el hombre se comprende plenamente y encuentra armonía, claridad y libertad respecto a todo vínculo extraño (ídem, pp.50-51).

\section{Una educación atenta al desarrollo evolutivo del niño}

Esta es la idea pedagógica central de Rousseau: el niño no es un adulto en pequeño, sino que su desarrollo pasa por etapas que la educación ha de tener en cuenta para adaptarse a sus capacidades en cada momento ${ }^{7}$. Siguiendo esa máxima,

\footnotetext{
7 Rousseau, admirado por Fichte en su escrito de 1793 Contribución a la rectificación del juicio del público sobre la Revolución Francesa (GA I/1, p.229), no es citado en estos Discursos porque era necesario evitar lo francés en este "libro de combate" (Philonenko, 1984, p.176), pero, según Philonenko, "una gran parte de las modificaciones aportadas a las tesis de Pestalozzi vienen de Rousseau, ya presente en las notas personales de Fichte en 1788. [...] Es necesario encontrar el
} 
Pestalozzi piensa igualmente que la educación del niño consiste en el desarrollo progresivo y sistemático de todas sus facultades, de modo que se esfuerza en confeccionar un método o arte pedagógico que se adapte a la evolución mental, psicológica y física del niño, es decir, a lo que él es capaz de aprender, comprender y hacer en cada etapa de su vida. Ésta es una idea que Fichte tenía que encontrar muy cercana a su método genético de filosofar, aunque éste se situaba en el plano transcendental y aquél en el empírico. "Tarde o temprano seguro que la naturaleza se vengará de todo lo que los hombres hagan en su contra", pensaba Pestalozzi, y por tanto hay que seguir su ritmo, observar una "gradación de las fuerzas y capacidades a desarrollar" y de los objetos a enseñar (Pestalozzi, 2009, p.163). La educación ha de mantener una armonía con la marcha de la naturaleza sensible, todos los principios pedagógicos han de estar acordes con sus leyes eternas (ídem, pp.83$85,148)$. "Solo la naturaleza nos hace buenos; únicamente ella nos conduce recta y firmemente a la sabiduría y a la verdad" (ídem, p.41), lo que no impide que se tenga que actuar en contra de algunas inclinaciones. Ha de haber por tanto una colaboración entre la naturaleza y el arte de educar, en la que el arte ayude y coopere con el desarrollo natural del educando y lo tenga en cuenta a la hora de introducir sus contenidos. Esta educación progresiva debe comenzar ya en la cuna (ídem, p.168), aprovechando el "inmenso círculo de los conocimientos intuitivos que la naturaleza lleva a la conciencia del niño desde su más tierna edad" (ídem, p.160), pues sea o no consciente de ello, "la madre instruye al niño desde el instante en que le toma en su regazo” (ídem, p.153).

Para descubrir las etapas de ese desarrollo del niño, Pestalozzi no partió de un sistema teórico, sino de sus experiencias (2012, pp.22-3). Mi método, nos dice, es "el producto de un empirismo limitado y extraordinariamente penoso, y -tengo que agregar- raramente afortunado" (Pestalozzi, 2009, pp.170-171). Buscaba las leyes psicológicas y físico-mecánicas del espíritu humano, de su organización general, de su intuición sensible y de su capacidad de conceptos, de su desarrollo y de su cultura, a fin de aplicar los mejores medios y técnicas educativas. "La esencia de la naturaleza, de donde emana la forma del desarrollo necesario a nuestra especie, es en sí misma eterna e inmutable y, referida a la educación, es y ha de ser su fundamento inmutable y eterno" (ídem, p.85; ver también 86-87). Por eso hay sólo un método pedagógico bueno: el que tiene en cuenta las leyes de la naturaleza (ídem, p.163). "Obra de modo que eleves el arte [...] a la necesidad física" (ídem, p.88) sería el imperativo pedagógico.

Rousseau pensaba que hay un despliegue sucesivo de las facultades en el ser

hombre nuevo de Rousseau en Pestalozzi y eso porque es indispensable permanecer en el espacio alemán" (ídem, p.192). Un panorama general de la influencia de Rousseau, que incluye también a Pestalozzi y a Fichte, se puede encontrar en Soëtard, 2012. 
humano: primero surgen las sensitivas, después las intelectuales y finalmente las sociales, morales y religiosas. Pero para Pestalozzi el despliegue de las facultades es simultáneo:

Un niño es un ser dotado con todas las facultades de la naturaleza humana, si bien ninguna de ellas ha alcanzado aún su desarrollo: es como un capullo no abierto aún. Cuando el capullo hace eclosión, se despliegan todas las hojas, sin que ninguna deje de hacerlo. Algo así debe ser el progreso de la educación. Ha de atenderse con idéntica solicitud a todas las capacidades de la naturaleza humana, pues sólo el cultivo simultáneo de todas ellas puede asegurar el éxito (2012, pp.9-10).

\section{La intuición como base de la educación}

Éste es un punto central para ambos pensadores. La pedagogía de Pestalozzi se la denomina justamente pedagogía de la intuición, porque él la pone a la base de todo proceso: "he asentado firmemente el principio más alto y supremo de la instrucción al reconocer a la intuición como el fundamento absoluto de todo conocimiento" (Pestalozzi, 2009, p.147); todo conocimiento debe partir de la intuición y referirse a ella (ídem, p.151). "La intuición no es otra cosa que la simple presentación a los sentidos de los objetos exteriores y la mera conciencia de su impresión. Con ella empieza la naturaleza toda instrucción” (ídem, p.153). La idea es que los niños no deben aprender palabras, frases y fórmulas cuyo contenido no comprendan y que únicamente puedan repetir de memoria como en charlatanes, el mal de nuestra escuela (ídem, pp.31 y 161). Como dijo Kant, pensamientos sin contenido sensible son vacíos (Crítica de la razón pura A 51, B 75). En eso consiste el método catequístico de la escuela, en repetir como papagayo palabras sin intuiciones (Pestalozzi, 2009, pp.60, 111 y 121). La intuición proporciona un contacto directo con lo real, con los objetos, y consigue que el educando sepa de qué se está hablando; por consiguiente, hay que tener un conocimiento intuitivo de los conceptos que usamos y la enseñanza de cualquier tema ha de comenzar por ella (ídem, p.161). "La exactitud de la intuición es el fundamento propio del juicio más exacto” (ídem, p.124). En consecuencia, el elemento esencial no es tanto la memoria, sino la comprensión mediante la intuición. "La primera regla a la que debe atenerse la madre es la de enseñar sirviéndose siempre de cosas más que de palabras" (Pestalozzi, 2012, p.115). Se ha de comenzar por aquello que el niño pueda tener experiencia sensible para ir después a las ideas. Lo contrario mata el espíritu, destruye en la especie humana la fuerza de la personalidad y la posibilidad de llegar a conceptos exactos (Pestalozzi, 2009, p.148), robándole toda capacidad intuitiva, hundiéndola en un estado antinatural (ídem, pp.150-1).

Se debe comenzar por la intuición, sí, pero la mera naturaleza nos va proporcionando intuiciones de un modo desordenado, azaroso, asistemático, 
irregular, confuso, fragmentario, lento (ídem, pp.122, pp.166-168). El mundo es "un mar moviente de intuiciones mezcladas unas con otras" y el arte de educar, en su colaboración con la naturaleza, tiene que introducir claridad, orden y relación (ídem, p.95). De ahí "la necesidad de una dirección psicológica desde sus años más tempranos para la intuición racional de todas las cosas" (ídem, p.37). El pedagogo ha de presentar al alumno las intuiciones en un orden lógico y psicológico, conforme a la evolución del niño, y de ese modo consigue también acelerar el aprendizaje. Ése es el orden: observación, descripción y conceptos, experimentación y razonamiento, a fin de pasar de intuiciones oscuras a conceptos claros (ídem, pp.160-6). Ese orden en el arte de enseñar, fundado en la organización general de nuestro espíritu, es el siguiente. Se tiene que "empezar por lo más bajo para llegar a lo alto" (ídem, p.35). Eso implica que se ha de ir de lo simple a lo complicado (ídem, p.40), como aconsejaba Descartes, y por tanto hay que reducir los conocimientos a sus elementos más simples, conocer éstos primero bien, y a partir de ahí caminar hacia lo más complejo, de manera que en el paso siguiente se añada algo más al anterior, pero acompañando, nunca violentando a los niños (ídem, pp.62-63). De igual modo se debe partir de las formas esenciales de las cosas, las cuales ejercen "una impresión más consistente sobre el alma del niño que sus circunstancias variables" (ídem, pp.89-90, 160), y conectar a ellas las cosas no esenciales, sin confundirlas. Con esa misma lógica, hay que tener en cuenta primero lo más próximo al niño, pues posee más intensidad, para pasar después a lo lejano, extendiendo cada vez más el círculo de la intuición y de los conceptos (ídem, pp.43, 87, 160). Igualmente se debe proporcionar libros intuitivos, ilustrados, no sólo con letras (ídem, pp.37-40, 43, 148-9), y subordinar la lectura al conocimiento del lenguaje, dado que la naturaleza va del sonido a la palabra, y de ésta al lenguaje, y de igual modo hacer depender la escritura del dibujo y éste del arte de la medida (ídem, p.94). Se ha de unir la intuición real de las cosas con el lenguaje y aprender a hablar antes que a leer. El razonar y juzgar vienen después, con el conocimiento maduro y completo, con el conocimiento de causas (G I, 47, 87, p.90). De ahí que Pestalozzi no fuera partidario del método socrático en los niños, pues se requiere para ello un desarrollo previo (ídem, pp.57-58).

Este principio de la intuición como base de un conocimiento de la realidad no podía ser sino alabado y subrayado por Fichte. Él, sobre todo en su enseñanza en Jena, ponía el acento en que todos los oyentes debían intuir aquello de lo que hablaba su Doctrina de la Ciencia: la actividad libre y espontánea del Yo, del espíritu, reflexionando sobre la propia actividad de pensar. Quien no alcanzara a captar en la intuición intelectual esa actividad, para ése no podía tener realidad aquello de lo que habla la Doctrina de la Ciencia, sino que se quedaría en una mera filosofía de fórmulas (Formular-Philosophie). En consecuencia, él era partidario de partir de 
una intuición viva y no quedarse en ninguna repetición de frases muertas y vacías (Aforismos GA II/7, 12-14). Se quejaba de que la presente generación no estaba preparada para su filosofía, porque "no participa ni es sensible a la intuición de la vida inmediata" (Patriotismo, GA II/9, p.430), sino se queda en fórmulas que no comprende (ídem, p.431). Felizmente el niño nace de por sí

con la capacidad y el impulso hacia la intuición. Ellos mismos no desean el mundo de sombras; es sólo nuestro desalmado arte [educativo] el que los impulsa hacia él en contra de su tendencia. Ese arte tiene que desaparecer y en su lugar ha de venir otro que los conduzca adecuadamente en la intuición, de manera que asegure su adherencia a la realidad y desarrolle su libertad para manejar la intuición adecuadamente. [...] que se aprenda las reglas del arte [pedagógico] de dirigir la intuición correctamente y de acuerdo con el orden natural (ídem, p.435).

En consecuencia, una pedagogía de la intuición como la de Pestalozzi era para él la mejor preparación para captar la realidad y comprender su propia filosofía (Fichte, 1988, pp.23-24): "el educando de nuestra educación se ha familiarizado ya desde un principio con el mundo de la intuición" y esa educación es la única posible para la filosofía (ídem, p.172).

\section{Una enseñanza activa}

Hemos visto que se ha de poner a la base del aprendizaje la intuición, o sea, el contacto directo y personal con la realidad, con vistas a alcanzar una compresión desde sí mismo e incluso pensar por uno mismo la realidad y no sólo por medio de la palabra de otro, que se queda por tanto vacía. Igualmente se ha expuesto la necesidad de acompañar pedagógicamente el desarrollo evolutivo del niño, mostrándole los conocimientos, actividades y sentimientos de los que él es capaz desde sí en cada etapa de su vida, a fin de desarrollar progresiva y simultáneamente todos los aspectos que configuran el ser humano. Pues bien, todo ello conduce al concepto de una pedagogía activa, que apela y se apoya en la actividad física y reflexiva del educando. Éste no debe limitarse a repetir mecánicamente lo leído o escuchado, sino que debe pasar a una elaboración propia de los contenidos, las actitudes, las valoraciones, los comportamientos. Hay que formar a seres humanos libres y capaces de hacer y de pensar por sí mismos. Pestalozzi propone que el niño descubra también las cosas por sí mismo (2012, pp.125-9), conducirles a la reflexión personal. "Buscaba únicamente la elevación de las fuerzas internas de los niños" (Pestalozzi, 2009, p.68), "fortalecer de un modo sencillo y general la capacidad íntima” (ídem, pp.59-60). El niño por naturaleza quiere aprender, y si está distraído y sin interés, el maestro debería empezar a buscar la causa en él mismo (Pestalozzi, 2012, p.122). No hay que implantar pasivamente los conocimientos, sino que los 
educandos deben adquirirlos mediante su actividad personal en la medida de sus capacidades y según su evolución natural (Pestalozzi, 2009, p.122), pues el fin de toda instrucción es "el desenvolvimiento de las capacidades y la precisión de los conceptos” (ídem, p.163). Pestalozzi propone y practica incluso la enseñanza de los alumnos menores por los más avanzados, también para solventar el problema de que él estaba solo con 80 niños de diversos niveles (ídem, pp.28-30). Por eso, otra de sus máximas pedagógicas reza así: "Obra también de modo que los resultados del arte y de la instrucción, elevados a la necesidad física, lleven impreso el sello de la libertad e independencia, mediante la riqueza y variedad en estímulos y juegos" (ídem, p.88).

Fichte no puede sino apoyar esta pedagogía que estimula y favorece la actividad creativa y libre del ser racional, pues el sujeto sólo puede comprender algo mediante su esfuerzo y su actividad ideal dentro de una acción práctica. En su filosofía lo primero no es la cosa, sino la acción, la acción propia del saber y de la libertad, que no pueden ser efecto de nada exterior. El saber parte desde sí como actividad espontánea, de manera que la enseñanza no puede ser mecánica, sino que en ella el niño debe emplear su propia fuerza espiritual (Aforismos GA II/7, p.13). En ese principio filosófico se basa la pedagogía de Pestalozzi. La forma de la nueva educación reside en que no procede arbitrariamente, como tampoco lo hace la subjetividad transcendental, sino conducida con seguridad por reglas firmes. Ella consiste en "estimular la actividad espiritual del educando, su pensamiento" (Fichte, 1988, p.162, véase también 43). Pestalozzi quiere intuición, e

introducir al educando en la intuición equivale al nuestro de estimular la actividad espiritual del mismo hacia el esbozo de imágenes, y sólo en esta creación libre, hacerlo aprender todo lo que aprende; pues la intuición sólo es posible a partir de aquello que se ha diseñado libremente (ídem, p.163; véase también pp.34-35).

Fichte introduce la actividad del espíritu no sólo al aprender desde la intuición, sino en la configuración misma de la intuición, que requiere igualmente una acción ideal del sujeto.

Es el ejercicio de esa actividad propia lo que produce el placer de estar siendo y de aprender y lo aviva poderosamente. "El educando siente placer al aprender [...] dado que cuando está aprendiendo es espontáneo y eso le produce ya el mayor placer" (ídem, p.35). Eso es lo que provoca esta nueva educación, que estimula la inclinación genuina por aprender, dado que impulsa la espontaneidad del educando y la convierte en la base de todo conocimiento, que hay que mantener por medio de avances regulados. Ésa es "la ley fundamental, eterna y de validez universal, de la naturaleza espiritual del hombre, la de tender directamente a la actividad espiritual" (ídem, p.36). La nueva educación se dirige a avivar adecuadamente esa actividad, que está en permanente desarrollo, conociendo sus leyes. Por el contrario, la educación 
que hasta ahora se ha practicado ha tenido como único objetivo la adquisición de una cantidad determinada de conocimientos de manera pasiva, mecánica y memorística; les era imposible captar el espíritu como principio autónomo y primordial de las cosas, y en consecuencia el educando aprendía de mala gana, poco y lentamente (ídem, pp.38-9). Por eso se servía de promesas de utilidad para la adquisición del honor o para el sustento futuro, o bien de castigos, puestos al servicio de lo material, y por tanto era incapaz de generar una mentalidad ética (ídem, p.40).

Sólo desarrollando la actividad espiritual mediante la enseñanza se produce el placer por el conocimiento en cuanto tal, manteniendo de ese modo el ánimo abierto a la formación ética, mientras que, por el contrario, la recepción puramente pasiva entumece y mata el conocimiento (ídem, pp.40-41).

El alumno de la nueva educación no olvidará lo aprendido, pues todo lo capta dentro de una coherencia y lo practica activamente y con placer interior (ídem, p.41).

\section{Referencias}

Fichte, J.G. (1964-2012). Gesamtausgabe. Stuttgart/Bad Cannstatt: FrommannHolzboog. Citaré esta obra como es preceptivo: GA, serie, tomo, página.

Fichte, J.G. (1988). Discursos a la nación alemana. Traducción de L.A. Acosta. Madrid: Tecnos.

Fichte, J.G. (2019). Doctrina de la Ciencia expuesta en su bosquejo general (1810). Traducción de Jacinto Rivera de Rosales. argumenta philosophica, 1, 7-21.

Fuchs, E. (ed.). (1978). J.G. Fichte im Gespräch 1. Stuttgart/Bad Cannstatt: Frommann-Holzboog.

Kant, I. Pedagogía. Akademie Ausgabe 9. Berlín: Walter de Gruyter.

Quintana Cabanas, J. Ma . (2013). Pensamiento pedagógico en el idealismo alemán y en Schleiermacher. Madrid: UNED.

Pestalozzi, J.H. (1949). Briefe 3. Zürich: Füssli.

Pestalozzi, J.H. (2009). Cómo Gertrudis enseña a sus hijos. Traducción de J.M. Quintana. Barcelona: PPU.

Pestalozzi, J.H. (2012). Cartas sobre la educación infantil. Traducción de J.M. Quintana. $3^{\mathrm{a}}$ ed. Madrid: Tecnos.

Rivera de Rosales, J. (2008). Nationalisme et cosmopolitisme. In: Goddard, J.Ch. et Rivera de Rosales, J. (ed.) Fichte et la politique (pp. 325-345). Monza, Italia: Polimetrica.

Rivera de Rosales, J. (2017). Fichte. Barcelona: RBA.

Rivera de Rosales, J. (2019a). La filosofía del segundo Fichte. argumenta philosophica, 1, 23-35.

Rivera de Rosales, J. (2019b). Fichte: la guerra verdadera y los principios del Estado de derecho (1813). In: Ferrer, D. (ed.). A filosofia da história e da cultura em Fichte (pp. 175-196) Coimbra, Portugal: Imprensa da Universidade de Coimbra. 
Fichte y Pestalozzi. Sobre la educación del pueblo

Philonenko, A. (1984). L'œuvre de Fichte. Paris : Vrin.

Soëtard, M. (ed.). (2012). Méthode et philosophie. La descendance éducative de l'Émile : Condorcet, Kant, Pestalozzi, Fichte, Herbart, Dilthey, Dewey, Freinet. Paris : L'Harmattan.

Taver, K. (2012). Fichtes Bildungsideal in den Reden an die deutsche Nation (1808) und der Rückgriff auf Pestalozzis Lehren. Fichte-Studien, 36, 417-429.

Tröhler, D. (2014). Pestalozzi y la educacionalización del mundo. Barcelona: Octaedro. 